\title{
Devising ethical codes for e-contents in e-learning
}

\author{
Aeen Mohammadi ${ }^{1}$, Rita Mojtahedzadeh ${ }^{1}$, Shadi Asadzandi*2,3 (1D) Hamed Rashidi $^{4}$
}

Received: 1 Sep 2018

Published: 2 Mar 2020

\section{Abstract}

Background: Promoting ethics is one of the goals of education, but the free flow of communication and divulging unethical behaviors in e-learning make the urgent need to clarify ethical values. Therefore, the aim of this study was to prepare ethical codes to develop and deliver e-contents.

Methods: A draft of e-content ethical codes was prepared based on the literature review. Then, it was further revised by e-learning, medical education, ethics, and e-content experts. Finally, the draft was finalized through a 2-round Delphi process among related experts all over the country.

Results: The final document of e-content ethical codes, including introduction, definitions, and 7 ethical code statements, was devised.

Conclusion: Considering the difference between e-content and other kinds of publications, this set of ethical codes can be used straightforwardly to assess ethical aspects of e-contents.

Keywords: Ethical codes, E-content, E-learning, Delphi method

Conflicts of Interest: None declared

Funding: This study was supported by Tehran University of Medical Sciences \& Health Services (Grant No: 95-04-176-33849).

\section{*This work has been published under CC BY-NC-SA 1.0 license.}

Copyright $\odot$ Iran University of Medical Sciences

Cite this article as: Mohammadi A, Mojtahedzadeh R, Asadzandi Sh, Rashidi H. Devising ethical codes for e-contents in e-learning. Med J Islam Repub Iran. 2020 (2 Mar);34:14. https://doi.org/10.47176/mjiri.34.14

\section{Introduction}

There are significant differences between keywords 'morale' and 'ethics'. The term morale implies the correct and wrong principles in behavior and deed, but the term ethics is a system that is based on a person or groups of people and includes the values or functional principles that has direct relationship with or without meticulousness of certain actions and their results (1). Nowadays, ethics is in the focus of attention and at the center of many developments worldwide. Mankind follows a rational and ethical approach to meet their physical and spiritual needs. Hence, the existence of ethics could be known as the center of future changes. This approach mostly affects the majors and services that are dependent on providing services (3).

Corresponding author: Shadi Asadzandi, sh-asadzandi@farabi.tums.ac.ir

1. Department of E-learning in Medical Education, Virtual School, Center for Excellence in E-learning in Medical Education, Tehran University of Medical Sciences, Tehran, Iran

2. School of Health Management and Information Science, Iran University of Medical Sciences, Tehran, Iran

3. Medical Library and Information Sciences, Virtual School, Tehran University of Medical Sciences, Tehran, Iran

4. English Language and Literature Faculty, University of Tehran, Tehran, Iran
For most of the professions and businesses, there are different ethical principles, regulations, and standards at the organizational, national and even international levels that have been developed under the title of professional ethics (4). Professional ethics are a set of dos and don'ts that address the experts of businesses and are related to their professional responsibilities (5). These principles can be helpful when there is a conflict between a particular activity and conflicting ethics in a profession. One of the instruments of establishing professional ethics is the ethical codes, which are a collection of principles and standards of peculiar human deportments which determine persons and groups' behaviors. As a matter of fact, in all professions, the dos and don'ts must be explicated in a ration-

$\uparrow$ What is "already known” in this topic:

Ethical codes and guidelines for publication had already been developed and approved by the Ministry of Health and Medical Education.

\section{$\rightarrow$ What this article adds:}

A set of ethical codes specific for e-contents, on which experts of the field agreed, was devised regarding copyright issues, elearning context, and target groups' needs. 
al process to provide the commonsense of values which must be kept and publicized in organizations (5). In occupations, which human relationships and relation with persons are more intense either as a customer or colleague, observing these principles seems to be more urgent (4); like the medical profession in which human relationships are crucially important in terms of the patient's mental or physical weakness. By all means, this issue pertains both to the medical profession and disciplines of this area, and even other fields of study such as nursing (6), engineering (7), research in medicine (8), genetics (9), psychology (10), and tens of other areas develop and administer their own regulations and ethics.

The advent of information technology and telecommunication has shone on all aspects of human and social life, and by removing the boarders and times, it has changed the world into a village (11). The limitations and physical areas of education as well as learning, like the walls of universities and classes, have been removed; therefore, education and learning are possible everywhere (12).These efforts have resulted in creating new concepts and areas titled as e-leaning, which is based on adaptation of computer technologies, multimedia, and processors. Using e-leaning has completely changed the teachercentered concept and process and modified the education style into a student-centered approach. E-leaning proposes a wide range of flexibility in teaching methodology, managing content, synchronous and asynchronous interaction between teachers and students, the organization and structure of the course, educational plans, and finally assessing and evaluating students (13). Moreover, e-leaning is not a separate concept from education; rather, it is another definition of it which takes place within a network where a collection of multimedia technologies and telecommunications are being engaged (14).

With the advent of e-learning, due to the close relationship with human information, ethical issues become more intense. Generally, the main aim of education is to promote ethics. However, the free stream of communication in virtual education and the incidence of immoral behaviors call for an extremely urgent action to adopt moral behaviors (15). The issues concerning technology ethics and electronic content (e-content) are various that each of which contains points and various subdivisions.

Thus, in this study, it was aimed to prepare ethical codes to develop and deliver e-contents.

\section{Methods}

This developmental research study was done in 3 steps.

Step 1: The first step was to prepare the first draft of ethical codes for e-content that included reviewing texts, library studies, extracting ethical concepts, and reviewing the ethical codes for publication (2), changing the concepts into ethical codes, and completing the content of the accomplished codes. Ethical codes and guidelines for publication that had already been developed and approved by the Ministry of Health and Medical Education were considered as the core resource to be justified for e-content.

Step 2: The second step was to form a specialized committee, including pundits in e-learning, and producing e-content and using specialists in ethics for holding specialized sessions to develop the drafts of ethical codes. First, these sessions were held in small panel discussions and, in the meantime, notetaking and recording the sessions were done. Then, this information was implemented and the major codes and themes were extracted qualitatively. The sessions were held 4 times.

Step 3: The third step was to validate the draft of codes and finalize them using the ideas of pundits all over the country, which was done using Delphi method. In this study, pundits referred to specialists in e-learning and medical education who were experienced in producing areas and the clinical specialists who were experienced in producing content and virtual teaching at least for one semester, and the specialists in ethics. These experts have been selected from the universities with active e-learning centers, including Tehran, Shahid Beheshti, Iran, Shiraz, Esfahan, Mashhad, Tabriz, Birjand, and Kerman Universities of Medical Sciences. The Delphi method was run twice, with 40 experts that expressed their no conflicting interests in Delphi questionnaire.

\section{Results}

First, all the electronic and published sources were reviewed. After searching in various databases, relevant concepts with e-content were extracted by 2 persons independently. Then, they compared their search results to ensure the accuracy of the extracted concepts. These concepts were prepared in a listed format from the beginning and some codes were considered for the concepts. The draft of ethical codes was compiled with 14 cases by the research team using this information. This step was finished in July 2017. Drafting ethical codes of e-contents was reviewed and discussed by applying the focus group method, including 14 e-learning experts. Four 3-hour sessions were held. Moreover, in addition to notetaking from the recommended cases, all the presented contents were recorded during the sessions. After reviewing the presented notes and information by researchers, the required items were added to the draft. Also, 2 more codes were added to the draft after focus group sessions. This step was performed in one month.

In the next step, to reach a consensus for the accuracy of the draft of ethical codes of e-contents, Delphi method was applied within which the opinions of 40 specialists in e-learning, medical education, ethics, and clinical sciences were used. Data were extracted, categorized, and collected in a list of opinions. Also, the views of the experts at the Minority of Health and consensus were identified. At last, by applying the intended changes, the information was sent to the participants to leave their comments at last opportunity. According to the latest opinions, in the last form, ethical codes of e-contents, including 7 items, were achieved (Table 1).

\section{Discussion}

Ethics have existed and regarded as the means for evaluating human deeds. Nowadays, ethical discussions are more important than ever. In different professions and majors, for functions and decisions to be homogeneous 


\section{Introduction}

Ethics is one of the most important discussions and subjects in academic environments that are under close observations of international communities, regional organizations, policymakers, planners, researchers, and specialists of different sciences and technologies among many countries. Moreover, the present age is the information age, and today's societies are called the information society; thus, the presence of information technologies and the discussion of e-learning has become increasingly important in today's world. By the emergence of various education methods, different types of contents and electronic sources, instructions and ethical recommendations to use, access, retrieve, and distribute them through having relation with humans have become more important. In Iran, e-learning has been developed more than before and producing different types of e-contents has become one of the daily routines in academic institutions. Thus, to maintain individual's rights, including patients, employees, and contents producers, the need for ethical codes is felt more than ever. In the past, the General Guide to Ethics in Medical Science Research, the National Guide to Ethics in Medical Science Research, and Ethics Guidelines have been developed in specific areas that should be followed in the production of electronic content. However, given the differences in the nature of electronic content of academic products of faculty members, specialized codes need to be developed. In this study, the country code of ethics has been codified and presented.

\section{Definitions}

E-content: It refers to all the educational contents including multimedia, graphics, texts, images, slides, animations, simulations, gamifications, references and the archived contents that are produced after individuals' interactions and performed in electronic format.

Intellectual property: It is the ownership of issues such as idea, invention or a process that is produced by means of intellect and thoughtful work.

\section{E-content ethical codes:}

1- The intellectual property right of e-content production, for both author(s) and custodian grant providers, is reserved and according to the both parties' agreement, it can be assigned to either of them or a third party as a publisher.

1.1- Individuals are known as authors of e-content who have major roles in at least one of the steps, a: designing e-content, b: preparing or teaching scientific contents. One of these authors is known as the corresponding author.

1.2- An unrealistic assignment to an individual or organization who is not involved in the preparation of content is improper.

1.3- The responsibility for observing the intellectual property rights and the principles of professional commitment is with e-content author(s).

1.4- The corresponding author must ensure the approval of the authors in a written form to add their names and meet their intellectual property rights according to their amount of participation.

1.5- It is better for the corresponding author to appreciate and acknowledge individuals who participated in a part of producing content such as theorizing, and other parts. However, the contribution is not sufficient enough to consider them as author.

1.6- The complete identity of author(s), including full name, affiliations, and education, must be mentioned in the content (2).

2- The major responsibility about the authenticity and keeping the proposed educational contents up to date at the time of producing them is on the author(s) and it should also be mentioned when updating or producing them.

3- All images, graphs, pictures, films and so forth used in e-content must be approved by the owner of the production and cited by its reference; and if these issues are the result of author(s) experiences and research, they should be clearly stated and if there is any interception, it should be announced.

4- All the authors of e-content should take the responsibility of their own part: (a) the authenticity of the included entries in the content, (b) commitment to the general and specific ethical guidelines of the country, and (c) stating potential interests' harassment in content.

4.1- The existence of interests' harassment is not potentially considered as ethical objection hindrance, but the author(s) must clearly state any type of interests' harassment that is not identified by the addressees.

4.2- The agreement between author(s) and financial supporter should not lead to not announcing any type of harassment (2).

5- Respecting the legal and ethical principles such as respecting social and cultural principles, avoiding any fake contents, avoiding insults and defamations, keeping the secrets of individuals, and maintaining privacy, are mandatory.

6- Using the films and pictures of persons must be such that they cannot result is one's recognition; meanwhile covering eyes is satisfactorily alone unless informed consent has been taken from individual. In other words, author(s) is responsible to inform these people of all the information that could affect their decisions to some extent.

6.1- Taking informed consent must be done without any coercion, threat, enticement, and temptation. Otherwise, the obtained consent is invalid (2).

6.2- Obtaining consent about vulnerable groups such as elderlies, pregnant women, protected children, mental handicaps, dementia sufferers, psychiatric patients, and other susceptible groups is subject to the general and specific ethical guidelines in Iranian medical sciences' studies.

7- In preparing e-content, following the rest of mentioned issues in nationally-approved general and specific ethical guidelines is mandatory.

and to prevent applying personal opinions and taking actions which are harmful for the beneficiaries, developing and following ethical codes are inevitable. The existence of these codes and their efficacies on persons involving in that area are effective $(16,17)$. Several ethical codes in technology and information security have been developed. This is mainly because of the presence of various information technology groups, as the result of which various opinions regarding the codes in this area have been developed. In the present study, these codes were reviewed analytically and the result of the reviews showed that the codes have dealt more to the security of data, users, skills and abilities, contracts, and costs (18-21). In Iran, the gen- eral guideline of ethics among medical sciences' studies, national ethics guideline in publishing medical sciences' productions, and national ethical guidelines in special areas have been already developed and approved. However, there are some differences between technology-based contents with other scientific publications that shows the necessity of devising specific ethical codes. In this study, a set of ethical codes for e-contents was developed. Some of the codes or statements were similar to ethical codes for publication (2), but some new codes were added, and some concepts changed or summarized with respect to econtent specifications. This document can be used straight forwardly for e-contents. 


\section{Conclusion}

Ethical codes that are suitable for the structures and methods of preparing these contents should be delivered to detect infringements and not to follow the principles and standards to approve them based on documents. In this study, the ethical codes of e-contents were produced with the cooperation of related experts which could be used either in national or international scales.

\section{Acknowledgments}

Researchers would like to thank Dr. Kiarash Aramesh, associate Professor of Medical Ethics and History of Medicine Research Center of TUMS, whose valuable comments improved the final draft of codes. This study was supported by Tehran University of Medical Sciences \& Health Services (Grant No: 95-04-176-33849).

\section{Conflict of Interests}

The authors declare that they have no competing interests.

\section{References}

1. Sabarinath B, Sivapathasundharam B. Ethics in dentistry. J Educ Ethics Dent. 2011;1(1):24.

2. Center EaMHR. National ethical guidelines for scientific publication: Ethics and Medical History Reasearch Center; 2018 [Available from: http://mehr.tums.ac.ir/ShowCode.aspx?CodeID= 118\&lang=fa.

3. Mokhtari Lakeh N, Nafar M, Ghanbari Khanghah A, Kazemnezhad Leili E. Nursing Students' views on Code of Ethics, Commitment to the Ethic of, Academic Dishonesty and Neutralization behaviors. J Holist Nurs Midwifery. 2014;24(3):64-71.

4. Izadikhah A, Changiz Yamani N, Mirshahjafarey I. Developing codes of ethics for clinical medicine educators. J Med Ethics Hist Med. 2013;6(1):37-52.

5. Rezaei Tavirani M. Professional ethics and its role in the medicine. Sci J Ilam Med Uni.1391:13-8. ( Persian)

6. Zahedi F, Sanjari M, Aala M, Peymani M, Aramesh K, Parsapour A, et al. The code of ethics for nurses. Iran J Public Health. 2013;42(Supple1):1.

7. Engineers NSoP. Code of Ethics for Engineers 2007 [Available from: https://www.nspe.org/sites/default/files/resources/pdfs/Ethics/CodeofEth ics/Code-2007-July.pdf.

8. Guraya SY, London NJM, Guraya SS. Ethics in medical research. J Med Uni. 2014;2(3):121-6.

9. Shuster J, FitzGerald K. Codes of Ethics for Genetics Professionals. eLS [Internet]. 201523 December 2017:[1-9 pp.]. Available from: http://onlinelibrary.wiley.com/doi/10.1002/9780470015902.a0005589.pu b3/full.

10. Association AP. Ethical principles of psychologists and code of conduct: American Psychological Association 2017 [Available from: http://www.apa.org/ethics/code/ethics-code-2017.pdf.

11. Ackoff RL. Re-creating the Corporation: A Design of Organizations for the 21st Century: Oxford University Press, USA; 1999.

12. Dargahi H, Ghazi Saidi M, Ghasemi M. The role of e-learning in Medical Sciences Universities. Payavard Salamat. 2008;1(2):20-9. (Persian)

13. Della Corte F, Mura FL, Petrino R. E-learning as educational tool in emergency and disaster medicine teaching. Minerva Anestesiol. 2005;71(5):181-96.

14. Shaihidi F, Zarif Sanaee N. Interaction in E-learning. Interdiscipl J Virtual Learn Med Sci. 2013;4(3):49-50.

15. Alipor A, Shalbaf O. Ethics in Virtual Teaching. Ethics in Science and Technology. 2008.

16. Alaeddini M, Moghadam SE. A report on the significance of ethics in dental research in Iran. J Dent Med. 2014;27(2):144-51.

17. Masumi SZZ, Bibalan FG, Roshanaei G. Observance of midwifery Code of Ethics among midwifery students and its related factors. Med Ethics J. 2016;10(35):11-30.
18. humanity IaTf. IEEE Code of Ethics: IEEE advancing Technology for humanity 2018 [Available from: https://www.ieee.org/about/ corporate/governance/p7-8.html.

19. Institute S. IT Code of Ethics 2004 [Available from: https://www.sans.org/security-resources/ethics.

20. ICCP - CERTIFIES IT MANAGEMENT B, DATA \& COMPUTER PROFESSIONALS. ICCP Code of Ethics 2018 [Available from: https://www.iccp.org/code-of-ethics-conduct-practice.html.

21. Technology IIo. Code of Ethics for IT Professionals (Undated) 2011 [Available from: http://ethics.iit.edu/ecodes/node/3115. 